\title{
Preparation and Standardization of Vaginal Suppository from Punica granatum Flower Extract Known as "Golnar" in Persian Medicine
}

\author{
Shamim Fayazmanesh ${ }^{1,2}$, Tayebeh Toliyat $^{2}$, Mahdieh Eftekhari ${ }^{3}$, Gholamreza Amin ${ }^{1}$, \\ Mannan Hajimahmoodi ${ }^{4}$, Mahnaz Khanavi ${ }^{1,5, *}$ \\ ${ }^{1}$ Department of Pharmacognosy, Faculty of Pharmacy and Persian Medicine and Pharmacy Research Center, Tehran University of \\ Medical Sciences, Tehran, IRAN \\ ${ }^{2}$ Department of Pharmaceutics, Faculty of Pharmacy, Tehran University of Medical Science, Tehran, IRAN. \\ ${ }^{3}$ Department of Pharmacognosy and Pharmaceutical Biotechnology, Faculty of Pharmacy, Kermanshah University of Medical Sciences, \\ Kermanshah, IRAN. \\ ${ }^{4}$ Drug and Food Control Department, Faculty of Pharmacy, Medical Sciences University of Tehran, Tehran, IRAN \\ ${ }^{5}$ Faculty of Land and Food Systems, University of British Columbia, Vancouver, BC, CANADA.
}

\begin{abstract}
Background: Punica granatum L. flower, known as "Persian Golnar", is used in Persian medicine to treat excessive menstrual bleeding. Most therapeutic activities of pomegranate are due to the presence of phenolic compounds such as ellagitannins and gallotannins. Aim: This study served the purpose of developing and standardizing $P$. granatum vaginal suppository. Materials and Methods: Total phenolic and tannin content were assessed for both the extract and the final formula. Moreover, physicochemical properties of vaginal suppository such as appearance, weight variation, melting point, and dissolution test were evaluated. Results and Discussion: It was indicated by the findings of this study that the odorless suppositories have a brownish-red color and uniform appearance with an average weight of $2.06 \pm 0.04$ and a melting time of 28.93 \pm 0.40 . $100 \%$ of the plant extract was released for up to $90 \mathrm{~min}$ after administration. The results also indicated that the average phenolic percentages of the extract and suppositories were $17.03 \%$ and $15.73 \%$ within three days respectively. Conclusion: $P$. granatum flower extract as a vaginal suppository can be applied as an anti-hemorrhagic agent due to the presence of polyphenols, particularly tannins, in the extract.
\end{abstract}

Key words: Menorrhagia, Punica granatum Flower, Vaginal Suppository, Total Phenolic Compounds, Total Tannins.

\section{INTRODUCTION}

Menorrhagia, as one the most common abnormalities of women's health, has multiple etiologies such as inflammation and structural uterine pathology. ${ }^{1}$ The management of menorrhagia is a necessity because of the upcoming serious problems such as anemia. ${ }^{2}$ Non-steroidal anti-inflammatory drugs (NSAIDs) are applied in menorrhagia but they have caused some serious side effects such as gastrointestinal disorders. $^{3}$

There have been many studies revealing that medicinal plants such as Annona senegalensis, Cissampelo smucronat, Cassytha filiformis,
Newboulda laevis are applied for menorrhagia due to their astringent activity. ${ }^{4}$ Many plants with high proportion of tannins show astringent properties and can commonly cause vasoconstriction activity as hemostatic agents. ${ }^{5}$ Moreover, in traditional manuscripts of Persian medicine several plants have been used to treat heavy menstrual bleeding. In Persian medicine, pomegranate flower known as "Persian Golnar" has been used for treating excessive menstrual bleeding. ${ }^{6-8}$ Punica granatum L. known as pomegranate is commercially planted for its edible fruit. It is usually cultivated in South East Asia,
Submission Date: 06-08-20 Revision Date: 18-01-21; Accepted Date: 19-05-21

DOI: 10.5530/ijper.55.3s.185 Correspondence: Dr. Mahnaz Khanavi, 'Department of Pharmacognosy, Faculty of Pharmacy and Persian Medicine and Pharmacy

Research Center, Tehran University of Medical Sciences, Tehran, IRAN.

${ }^{5}$ Faculty of Land and Food Systems, University of British Columbia, Vancouver, BC, CANADA.

Phone:

0098-21-66575380,

Email - khanavim@tums.ac.ir

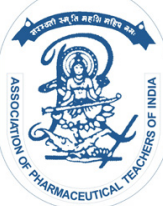

www.ijper.org 
Mediterranean region and the United States. ${ }^{9}$ Some biological activities of P. granatum have been reported. Quite a lot of studies have been published on antioxidant, ${ }^{10}$ anti-carcinogenic ${ }^{11}$ and anti-inflammatory ${ }^{12}$ effects of pomegranate components. Pomegranate possesses lots of medical applications, e.g. cardiovascular diseases, diabetes, alzheimer, dental conditions, erectile dysfunction, male infertility, arthritis, obesity and protection from ultraviolet (UV) radiation. ${ }^{13}$ Most therapeutic activities of pomegranate result from the presence of phenolic compounds such as ellagitannins and gallotannins. ${ }^{14}$

According to the traditional background of $P$. granatum and its pharmacologic properties such as anti-hemorrhagic, anti-oxidant and anti-inflammatory activities, the present study investigated the preparation and standardization of vaginal suppository formula of P. granatum flower extract.

\section{MATERIALS AND METHODS}

\section{Ethical Considerations}

The present study was approved by the Ethics Committee of Pharmaceutical Science Research Center of TUMS with the code of IR.TUMS.PSRC.REC.1394, 22 on $2015 / 10 / 25$.

\section{Preparation and Authentication of the Plant}

Punica granatum flowers were purchased from a local herbal drug market (Tehran, Iran). The sample was identified by Professor G. Amin and deposited at the Herbarium of Faculty of Pharmacy, Tehran University of Medical Sciences (PMP-530). The flowers were powdered using a grinder.

All chemicals and reagents were of analytical grade from Merck (Munich, Germany) and Sigma Aldrich (Milan, Italy) companies.

\section{Extract Preparation}

One hundred $\mathrm{g}$ of powdered flowers were extracted with hydro-alcoholic solvent (ethanol 70\%) using maceration method at room temperature for three days. The extract was condensed by rotary evaporator under $40^{\circ} \mathrm{C}$ and then lyophilized. The brownish-red extract (extractionyield $=45 \%$ ) was obtained and kept in fridge for further experiments. ${ }^{15}$

\section{Total Phenolic Content}

According to the Folin-Ciocalteu method with some changes, total phenolic compounds were performed. Two hundred $\mu \mathrm{L}$ of the ethanol extract were mixed with $1.5 \mathrm{ml}$ of tenfold diluted Folin-Ciocalteu reagent. The mixture was kept at room temperature for $5 \mathrm{~min}$ and then $1.5 \mathrm{ml} \mathrm{Na}_{2} \mathrm{CO}_{3} 7.5 \%$ solution was added.
The mixture was also kept at room temperature. After $90 \mathrm{~min}$, the absorbance level was evaluated at $725 \mathrm{~nm}$ using a UV-Visible spectrophotometer (GBC, Cintra 40). Total phenolic content was quantified by calibration curve obtained by evaluating the absorbance of the known concentrations of gallic acid standard solutions [10 - $150 \mu \mathrm{g} \mathrm{mL}-1$ in $80 \%$ methanol]. The results were determined as gallic acid equivalent (GAE) per one-gram dry powder and reported as mean value \pm standard deviation $(\mathrm{SD}) .{ }^{16}$

\section{Tannin Assay}

Determination of total tannin content of the sample was performed according to Hajimahmoodi et al. 2013. Three $\mathrm{g}$ of the flower powder were mixed with $250 \mathrm{~mL}$ of deionized double distilled water. Then the mixture was filtered through sample filter (Control Biogen-Spain). Twenty-five $\mathrm{mL}$ of the infusion were poured into $1 \mathrm{~L}$ conical flask and then equal volume of indigo solution [0.6\%] and $750 \mathrm{~mL}$ deionized distilled water were added. The final solution was titrated with KMNO4 (0.1 $\mathrm{N}$ aqueous solution) until the blue colored solution turned into a golden yellow color. The blank test was performed by titration of the mixture of $25 \mathrm{~mL}$ indigo carmine and $775 \mathrm{~mL}$ double distilled water. All samples were done in triplicates. The tannin percentage [\%] in the samples was estimated as follows:

$$
\mathrm{T}(\%)=[\mathrm{V}-\mathrm{V} 0] 0.004157 \times 250 \times 100 / \mathrm{g} \times 25
$$

Where $\mathrm{V}$ is the volume of $\mathrm{KMNO}_{4}(0.1 \mathrm{~N}$ aqueous solution) applied in the sample titration; $\mathrm{V0}$ is the volume of $\mathrm{KMNO}_{4}$ used in the titration of the blank as $\mathrm{mL} ; \mathrm{g}$ as gram is the mass of the sample taken for the analysis. ${ }^{17}$

\section{Formulation of Vaginal Suppositories}

Final plant extraction was formed as vaginal inserts with water base. The weight of each suppository was $2 \mathrm{~g}$. Formulation of suppository was prepared by total extract of P. granatum flowers (10\%), tween 80, PEG 4000, PEG 400 and distilled water. The inserts were made with 3 different proportions from PEG 4000 to PEG 400 (95\%, 90\%, 85\%).

\section{Physicochemical Properties}

The following experiments were conducted on suppositories. The prepared suppositories were evaluated for physicochemical parameters via organoleptic properties, weight variation, melting time and in-vitro drug release. The tests were carried out several times and the results were tabulated. 


\section{Organoleptic Properties}

The suppositories have a uniform appearance. The color of them is brownish-red because of the P. granatum flower extract. Also, the suppositories were odorless.

\section{Weight Variation}

According to BP pharmacopeia, twenty suppositories were randomly selected and weighted. Then, their average weight and percentage deviation value was determined. There must be no more than two suppositories differing from the average weight by more than $5 \%$ and no suppositories differing from the average weight by more than $10 \% .^{18}$

\section{Melting Time}

Melting Time is the measuring time for all suppositories to melt or disperse when immersed in water bath kept at $37 \pm 1^{\circ} \mathrm{C} .{ }^{19-22}$

\section{Tannin and Phenolic Content Assay in Suppository}

Based on the method described previously, the amount of tannin and phenolic contents in suppositories was determined.

\section{Dissolution Test of Suppositories}

One of the most important quality control tools for evaluation in vitro is Dissolution Test. ${ }^{19}$ The rate of drug release was measured in the $500 \mathrm{ml}$ of water dissolution medium at a temperature of $37 \pm 0.5^{\circ} \mathrm{C}$ for $90 \mathrm{~min}$ at a speed of $50 \mathrm{rpm} / \mathrm{min}$ with USP pharmacopoeia No.1 dissolution apparatus (basket method) and a sampling time interval of $15 \mathrm{~min}$. Finally, the amount of plant extract released from the suppository was calculated at certain times. The samples were then centrifuged and diluted and the amount of total phenol content was determined by spectrophotometric measurement at $725 \mathrm{~nm}$ by UV-Visible spectrophotometer. The mean and standard deviation of the released extract were calculated and the percentage of releasing was plotted against time.

This test was performed on all three different percentages of suppositories (85\%, 90\% and 95\%) and a comparison was made between the release rates of the extract from suppositories at certain times.

\section{RESULTS AND DISCUSSION}

\section{Total Tannin Content}

As shown in Table 1, total tannin contents of the extract and the formulation were assessed. Total tannin contents of extract and suppository were $5.04 \pm 0.053$ and $4.73 \pm 0.23$ respectively.

\begin{tabular}{|c|c|c|}
\hline \multirow{2}{*}{$\begin{array}{c}\text { Table 1: Total tannin content of Punicagranatum } \\
\text { flower extract and suppository. }\end{array}$} \\
\cline { 2 - 3 } Sample & \multicolumn{2}{|c|}{ Total tannin percentage (\%) } \\
\cline { 2 - 3 } & P. granatum extract & Suppository \\
\hline 1 & 5.1 & 4.53 \\
\hline 2 & 5.05 & 4.99 \\
\hline 3 & 4.97 & 4.67 \\
\hline SD & 0.053 & 0.23 \\
\hline Mean & 5.04 & 4.73 \\
\hline
\end{tabular}

\begin{tabular}{|c|c|c|c|}
\hline \multicolumn{4}{|c|}{ Table 2: Total phenolic content of Punicagranatum } \\
flower extract in three different days. \\
\hline & First day & Second day & Third day \\
\hline \multirow{2}{*}{$\begin{array}{c}\text { Total } \\
\text { phenolic } \\
\text { content of } \\
\text { the extract } \\
\text { (mg/l) }\end{array}$} & 0.1706 & 0.1715 & 0.1689 \\
\cline { 2 - 4 } & 0.1697 & 0.1724 & 0.1695 \\
\hline Mean & 0.1702 & 0.1706 & 0.1694 \\
\hline SD & 0.1702 & 0.1715 & 0.1693 \\
\hline $\begin{array}{c}\text { Mean } \\
\text { percentage } \\
\text { of phenolic } \\
\text { content (\%) }\end{array}$ & 17.02 & 0.706 & 0.245 \\
\hline
\end{tabular}

\section{Determination of total phenolic content}

As seen in Tables 2 and 3, the total phenolic content of pomegranate flower extract and the formulation were declared in terms of gallic acid equivalent. The average phenolic percentage of the extract and suppository within three days were $17.03 \%$ and $15.73 \%$ respectively.

\section{Determination of Weight Variation}

According to Table 4, there were no more than 2 suppositories differing from the average weight by more than 5\% and no suppository differing from the average weight by more than $10 \%$. Their average weight was $2.06 \pm 0.046$.

\section{Determination of Melting Point}

As shown in Table 5, melting point was assessed in triplicate and the obtained mean was $28.93 \pm 0.404$.

\section{In vitro Release of Extract from Suppository}

According to Figure 1, the amount of released extract from samples was measured based on the percentage of released total phenolic. The samples were then centrifuged and diluted and the amount of total phenol content was determined by spectrophotometric measurement at $725 \mathrm{~nm}$ by UV-Visible spectrophotometer.

This test was performed on all three different percentages of suppositories $(85 \%, 90 \%$ and $95 \%)$ and a comparison 


\begin{tabular}{|c|c|c|c|}
\hline & First day & Second day & Third day \\
\hline \multirow{3}{*}{$\begin{array}{l}\text { Total phenolic } \\
\text { content of the } \\
P . \text { granatum } \\
\text { suppository } \\
\text { (mg/l) }\end{array}$} & 0.1589 & 0.1548 & 0.1579 \\
\hline & 0.1593 & 0.1553 & 0.1581 \\
\hline & 0.1586 & 0.1549 & 0.1583 \\
\hline Mean & 0.1589 & 0.1550 & 0.1581 \\
\hline SD & 0.238 & 0.216 & 0.208 \\
\hline $\begin{array}{c}\text { Mean } \\
\text { percentage } \\
\text { of phenolic } \\
\text { content of the } \\
\text { suppository } \\
\text { (\%) }\end{array}$ & 15.89 & 15.50 & 15.81 \\
\hline
\end{tabular}

Table 4: Weight variation (g) for 20 suppositories.

\begin{tabular}{|l|l|l|l|l|l|l|l|l|l|}
\hline 2.00 & 1.99 & 2.01 & 2.04 & 2.03 & 1.97 & 2.00 & 2.01 & 2.05 & 1.98 \\
\hline 2.10 & 2.15 & 1.98 & 2.04 & 1.99 & 2.00 & 2.12 & 2.12 & 2.00 & 2.04 \\
\hline
\end{tabular}

\begin{tabular}{|c|c|}
\hline \multicolumn{2}{|c|}{$\begin{array}{c}\text { Table 5: Melting point of Punica granatum } \\
\text { suppository at temperature } \mathbf{3 7} \pm \mathbf{1}^{\circ} \mathbf{C} \text {. }\end{array}$} \\
\hline P. granatum suppository & Melting Time (minute) \\
\hline 1 & 28.5 \\
\hline 2 & 29.3 \\
\hline 3 & 29 \\
\hline SD & 0.404 \\
\hline Mean & 28.93 \\
\hline
\end{tabular}

was made between the release rates of the extract from suppositories at certain times. Based on the statistical studies, it can be concluded that the amount of final release of the plant extract, $75 \mathrm{~min}$ after suppository administration in the bases of $85 \%, 90 \%$ and $95 \%$, was not statistically significant and in all the bases $100 \%$ of the plant extract was released up to 90 min after administration (Figure 1).

P. granatum flowers contain many polyphenols such as tannins including ellagitannins and gallotannins. Pomegranate ellagitannins such as punicalagin exerted significant anti-oxidant and anti-inflammatory activities. ${ }^{20,21}$ Punicalin, another ellagitannin isolated from pomegranate, showed inhibitory effect on carrageenan-induced inflammation in the rat. ${ }^{22}$ The extracts of pomegranate possess potent anti-inflammatory effect. ${ }^{23}$ Furthermore, because of their astringent effect, tannins are used as vasoconstrictors. ${ }^{24}$ Previous studies have shown that tannin-rich plants possess anti-hemorrhagic effect. Some reports exhibited that the presence of tannins

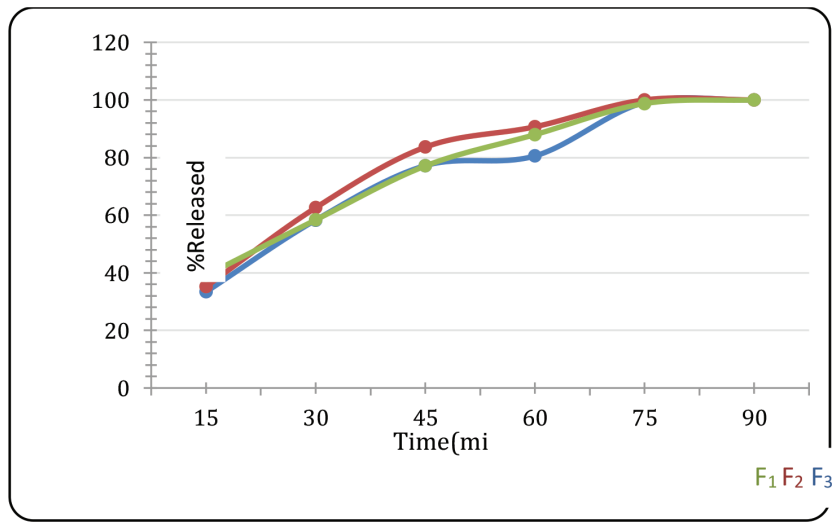

Figure 1: Comparison of average release of extract (total phenol content) from all three formulations. F1) suppository $85 \%$ F2) suppository $90 \%$ F3) suppository $95 \%$

could be responsible for the anti-hemorrhagic effect of plants. ${ }^{4,25}$ Gopalakrishnan et al. introduced ellagic acid as an effective anti-hemorrhagic agent. ${ }^{26}$ Moreover, presence of phytosterols is proven in pomegranate. A clinical trial on the herbal formula containing pomegranate revealed that the formula regulated hormone in follicular phase due to the presence of phytoestrogen compounds. ${ }^{27}$ Similar to our study, another clinical study showed that oral administration of $P$. granatum flowers has shown significant antihemorrhagic activity against heavy menstrual bleeding of endometrial origin compared to tranexamic acid. ${ }^{28}$

Elfalleh et al. (2012) depicted that the total phenolic and tannin contents of pomegranate flower extract were 66.29 (GAE mg/g dry weight) and 148.24(TAE mg/g dry weight) respectively which is more than the result of this study. ${ }^{29}$

Similar to our study, Mahboubi et al. (2015) exhibited that methanol fraction of pomegranate flower contained $18.1 \mathrm{mg} \mathrm{GEA} / \mathrm{g}$ total phenolic content. ${ }^{30}$

According to our findings, the total phenolic content of the extract is slightly higher than the total phenolic content of the suppository; however, the difference is not statistically significant. It could be due to the presence of suppositories' excipients that have prevented the release of the total phenolic compounds. It seems that the prepared suppositories show a suitable formulation due to the short release time of phenolic compounds (90 min). Also, reducing the release time could improve patient compliance and formulation effectiveness.

Limitations of the study include the provision of plant raw materials as well as maintaining the stability of active ingredients in the finish product. 


\section{CONCLUSION}

According to our results and traditional background, Punica granatum flower extract as vaginal suppository can be applied as an anti-hemorrhagic agent due to the presence of polyphenols in the extract, particularly tannins. Further stability studies and clinical trials of the formulation can be considered in the future.

\section{ACKNOWLEDGEMENT}

The study was derived from part of a thesis by Shamim Fayazmanesh and has been supported by the Research Vice Chancellor of Tehran University of Medical Sciences, Tehran, Iran (TUMS); (Grant number 91-0496-2000).

\section{CONFLICT OF INTEREST}

The authors declare that they have no conflict of interest.

\section{ABBREVIATIONS}

GAE: Gallic acid equivalent; PEG: Polyethylene glycol.

\section{REFERENCES}

1. Bieniasz J, Zak T, Laskowska-Zietek A, Noczyńska A. Causes of menstrual disorders in adolescent girls--a retrospective study. Endokrynologia, diabetologiaichorobyprzemianymateriiwiekurozwojowego: organ Polskiego TowarzystwaEndokrynologowDzieciecych. 2006;12(3):205-10.

2. Sobota A, Neufeld EJ. Recognition and management of immune thrombocytopenic purpura and autoimmune hemolytic anemia in the emergency department. Clin Pediatr Emerg Med. 2011 Sep 1;12(3):245-52. doi: 10.1016/j.cpem.2011.07.004.

3. Lethaby A, Duckitt K, Farquhar C. Non-steroidal anti-inflammatory drugs for heavy menstrual bleeding. Cochrane Database Syst Rev. 2013;1. doi: 10.1002/14651858.CD000400.pub3.

4. Dandjesso C. Phytochemistry and hemostatic properties of some medicinal plants sold as anti-hemorrhagic in Cotonou markets (Benin). Indian J Sci Technol;5(8):1-5. doi: 10.17485/ijst/2012/v5i8.10.

5. Pascal C, Poncet-Legrand C, Cabane B, Vernhet A. Aggregation of a prolinerich protein induced by epigallocatechin gallate and condensed tannins: effect of protein glycosylation. J Agric Food Chem. 2008 Aug 13;56(15):6724-32. doi: 10.1021/jf800790d, PMID 18642847.

6. Qanoon SI. In Persian, Tehran: Soroush. 2016.

7. ExirAzam JN. Vol. 2. Tehran: Iran University of Medical Sciences; 2008. p. 986-91.

8. Jorjani E, Kharazmshahi Z-Y, Mohhareri M, editors. Vol. 1. Tehran: Academy of Medical Sciences of IR Iran; 2002. p. 163.

9. Ferrara G, Cavoski I, Pacifico A, Tedone L, Mondelli D. Morpho-pomological and chemical characterization of pomegranate (Punica granatum L.) genotypes in Apulia region, Southeastern Italy. Sci Hortic. 2011 Sep 30;130(3):599-606.

10. Singh RP, Chidambara Murthy KN, Jayaprakasha GK. Studies on the antioxidant activity of pomegranate (Punica granatum) peel and seed extracts using in vitro models. J Agric Food Chem. 2002 Jan 2;50(1):81-6. doi: 10.1021/jf010865b, PMID 11754547.

11. Sharrif MM, Hamed HK. Chemical composition of the plant Punica granatum L.(pomegranate) and its effect on heart and cancer. J Med Plants Res. 2012 Oct 17;6(40):5306-10. doi: 10.5897/JMPR11.577.
12. Lee CJ, Chen LG, Liang WL, Wang CC. Anti-inflammatory effects of Punica granatum Linne. in vitro and in vivo. Food Chem. 2010 Jan 15;118(2):315-22. doi: 10.1016/j.foodchem.2009.04.123.

13. Jurenka J. Therapeutic applications of pomegranate (Punica granatum L.): a review. Altern Med Rev. 2008 Jun 1;13(2).

14. Gil MI, Tomás-Barberán FA, Hess-Pierce B, Holcroft DM, Kader AA Antioxidant activity of pomegranate juice and its relationship with phenolic composition and processing. J Agric Food Chem. 2000 Oct 16;48(10):4581-9. doi: 10.1021/jf000404a, PMID 11052704.

15. Eftekhari M, Ardekani MS, Amini M, Akbarzadeh T, Safavi M, Karimpour E, Khanavi M. Biological activities of the essential oil and total extract of Salvia macrosiphonBoiss. J Basic Clin Pharm. 2017 May 15;8(2).

16. Hajimahmoodi M, Faramarzi MA, Mohammadi N, Soltani N, Oveisi MR, Nafissi-Varcheh N. Evaluation of antioxidant properties and total phenolic contents of some strains of microalgae. J Appl Phycol. 2010 Feb 1;22(1):43-50. doi: 10.1007/s10811-009-9424-y.

17. Hajimahmoodi M, Moghaddam G, Ranjbar AM, Khazani H, Sadeghi N, Oveisi MR, Jannat B. Total Phenolic, Flavonoids, Tannin Content and Antioxidant Power of Some Iranian Pomegranate Flower Cultivars (\&lt;i\&gt;Punica granatum\&lt;/i\&gt; L.). Am J Plant Sci. 2013;04(9):1815-20. doi: 10.4236/ajps.2013.49223.

18. Pharmacopia B. London: British Pharmacopoeia. Her Majesty's Stationery Office; 1998.

19. Allen L. Suppositories. London: Pharmaceutical Press; 2007.

20. Cerdá B, Espín JC, Parra S, Martínez P, Tomás-Barberán FA. The potent in vitro antioxidant ellagitannins from pomegranate juice are metabolised into bioavailable but poor antioxidant hydroxy-6H-dibenzopyran-6-one derivatives by the colonic microflora of healthy humans. Eur J Nutr. 2004 Aug 1;43(4):205-20. doi: 10.1007/s00394-004-0461-7, PMID 15309440.

21. Adams LS, Seeram NP, Aggarwal BB, Takada Y, Sand D, Heber D. Pomegranate juice, total pomegranate ellagitannins, and punicalagin suppress inflammatory cell signaling in colon cancer cells. J Agric Food Chem. 2006 Feb 8;54(3):980-5. doi: 10.1021/jf052005r, PMID 16448212. Adams LS, Seeram NP, Aggarwal BB, Takada Y, Sand D, Heber D. Pomegranate juice, total pomegranate ellagitannins, and punicalagin suppress inflammatory cell signaling in colon cancer cells. J Agric Food Chem. 2006 Feb 8;54(3):980-5. doi: 10.1021/jf052005r, PMID 16448212.

22. Lin CC, Hsu YF, Lin TC. Effects of punicalagin and punicalin on carrageenaninduced inflammation in rats. Am J Chin Med. 1999;27(3-4)(03n04):371-6. doi: 10.1142/S0192415X99000422, PMID 10592846.

23. Ismail T, Sestili P, Akhtar S. Pomegranate peel and fruit extracts: a review of potential anti-inflammatory and anti-infective effects. J Ethnopharmacol. 2012 Sep 28;143(2):397-405. doi: 10.1016/j.jep.2012.07.004, PMID 22820239.

24. Furlan CM, Barbosa L, Alves DY. Tannins: what do they represent in plant life. Tannins: types, foods containing and nutrition. New York: Nova Science Publishers, Inc; 2011. p. 251-63.

25. Odukoya OA, llori OO, Sofidiya MO. Astringent herbs as vasoconstrictors in haemorrhoid therapy. Planta Med. 2007;73(9):P_231. doi: 10.1055/s-2007987012.

26. Gopalakrishnan L, Ramana LN, Sethuraman S, Krishnan UM. Ellagic acid encapsulated chitosan nanoparticles as anti-hemorrhagic agent. Carbohydr Polym. 2014 Oct 13;111:215-21. doi: 10.1016/j.carbpol.2014.03.093, PMID 25037345.

27. Yarnell E, Abascal K. Multiphasic herbal prescribing for menstruating women. Altern Complement Ther. 2009 Jun 1;15(3):126-34. doi: 10.1089/ act.2009.15305.

28. Goshtasebi A, Mazari Z, Behboudi Gandevani SB, Naseri M. Antihemorrhagic activity of Punica granatum L. flower (Persian Golnar) against heavy menstrual bleeding of endometrial origin: a double-blind, randomized controlled trial. Med J Islam Repub Iran. 2015;29:199. PMID 26157717.

29. Elfalleh W. Total phenolic contents and antioxidant activities of pomegranate peel, seed, leaf and flower. J Med Plants Res. 2012 Aug 31;6(32):4724-30. doi: 10.5897/JMPR11.995.

30. Mahboubi A, Asgarpanah J, Sadaghiyani PN, Faizi M. Total phenolic and flavonoid content and antibacterial activity of Punica granatum L. var. pleniflora flowers (Golnar) against bacterial strains causing foodborne diseases. BMC Complement Altern Med. 2015 Dec 1;15(1):366. doi: 10.1186/ s12906-015-0887-x. 


\section{PICTORIAL ABSTRACT}
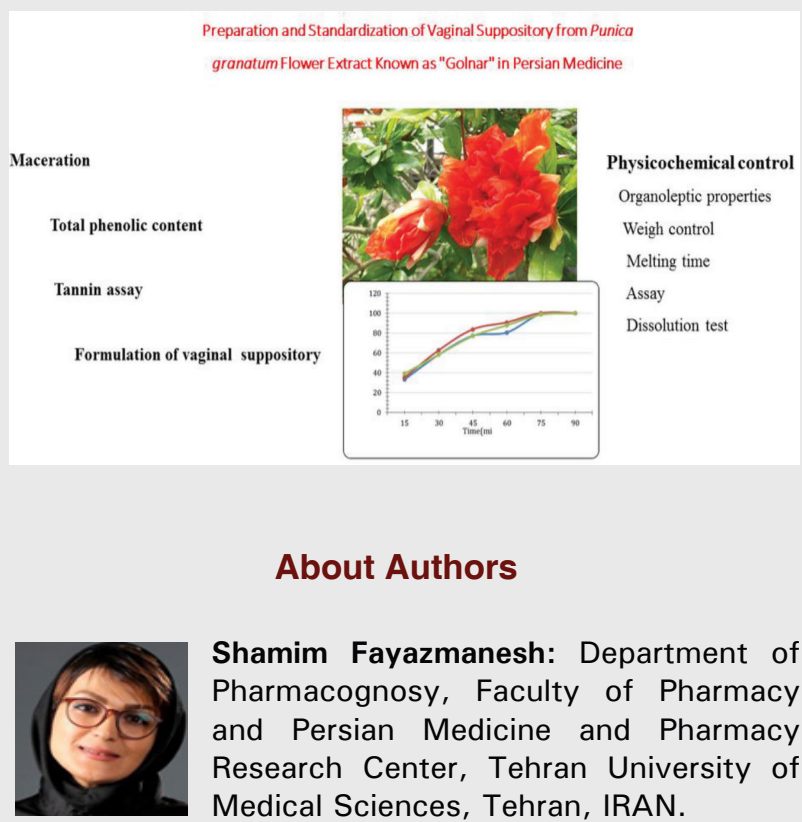

Shamim Fayazmanesh: Department of Pharmacognosy, Faculty of Pharmacy and Persian Medicine and Pharmacy Research Center, Tehran University of Medical Sciences, Tehran, IRAN.

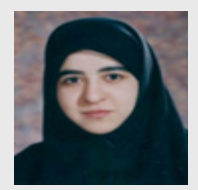

Tayebeh Toliyat: Department of Pharmaceutics, Faculty of Pharmacy, Tehran University of Medical Science, Tehran, IRAN.

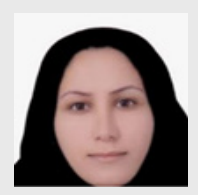

Mahdieh Eftekhari: Department of Pharmacognosy and Pharmaceutical Biotechnology, Faculty of Pharmacy, Kermanshah University of Medical Sciences, Kermanshah, IRAN.

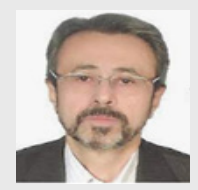

Gholamreza amin: Department of Pharmacognosy, Faculty of Pharmacy and Persian Medicine and Pharmacy Research Center, Tehran University of Medical Sciences, Tehran, IRAN.

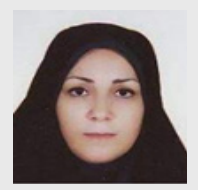

Mannan Hajimahmoodi: Drug and Food Control Department, Faculty of Pharmacy, Medical Sciences University of Tehran, Tehran, IRAN.

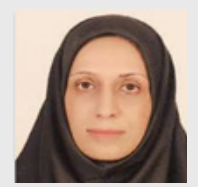

Mahnaz Khanavi: Department of Pharmacognosy, Faculty of Pharmacy and Persian Medicine and Pharmacy Research Center, Tehran University of Medical Sciences, Tehran, IRAN.

\section{SUMMARY}

Punica granatum L. flowers known as "Persian Golnar" has been used in Persian medicine to treating excessive menstrual bleeding. Most therapeutic activities of pomegranate are due to the presence of phenolic compounds such as ellagitannins and gallotannins. The purpose of this study was to develop and standardize P. granatum vaginal suppository. Total phenolic and tannin content was assessed for both the extract and the final formula. Moreover, physicochemical properties of vaginal suppository such as appearance, weight variation, melting point and dissolution test were evaluated. The findings of this study indicated that the odorless suppositories have a brownish-red color and uniform appearance. Their average weight and melting point was $2.06 \pm 0.04$ and $28.93 \pm 0.40$ respectively and $100 \%$ of the plant extract was released for up to $90 \mathrm{~min}$ after administration. Moreover, the results indicated that the average phenolic percentage of the extract and suppositories was $17.03 \%$ and $15.73 \%$ within three days respectively. The extract of $P$. granatum flowers as vaginal suppository can be applied as an anti-hemorrhagic agent due to the presence of polyphenols, particularly tannins, in the extract.

Cite this article: Fayazmanesh S, Toliyat T, Eftekhari M, Amin G, Hajimahmoodi M, Khanavi M. Preparation and Standardization of Vaginal Suppository from Punica granatum Flower Extract Known as "Golnar" in Persian Medicine. Indian J of Pharmaceutical Education and Research. 2021;55(3s):s784-s789. 